\title{
PEMILIHAN SMA(SEKOLAH MENENGAH ATAS) SWASTA MENGGUNAKAN METODE CPI(COMPOSITE PERFORMANCE INDEX)
}

\author{
Andri Anto Tri Susilo', Lukman Sunardi ${ }^{2}$ \\ ${ }^{123}$ Program Studi Informatika - Universitas Bina Insan Lubuklinggau \\ Email:1andrianto@univbinainsan.ac.id, 2lukmansunardi@univbinainsan.ac.id
}

\begin{abstract}
Abstrak
Pemilihan sekolah merupakan masalah utama bagi orangtua disimpulkan dari hasil beberapa pertanyaan kepada orangtua. Banyaknya pilihan sekolah yang masing-masing memiliki kelebihan dan kekurangan serta kurang objektifnya data hasil analisa sehingga perlu dievaluasi berulangulang. SMA(Sekolah Menengah Atas) merupakan jenjang pendidikan menengah atas pada pendidikan formal setelah lulus SMP (Sekolah Menengah Pertama). Jumlah siswa yang melanjutkan pendidikanke SMA Negeri sekitar $70 \%$ dan 30\% sisanya akan melanjutkan pendidikan ke SMA Swasta. Bagi siswa yang akan melanjutkan pendidikan ke SMA swasta, orang tua dan siswa tersebut dipusingkan dengan banyaknya pilihan SMA swasta yang ada dengan berbagai keunggulan dan kekurangan. Metode CPI(Composite Performance Index) digunakan untuk memilih beberapa alternatif. Teknik CPI merupakan indeks gabungan (Composite Index) yang dapat digunakan untuk menentukan penilaian atau peringkat dari berbagai alternatif(i)
\end{abstract}

Kata Kunci : Siswa; SMA; CPI

\begin{abstract}
School selection is a major problem for parents as concluded from the results of several questions to parents. There are many choices of schools, each of which has advantages and disadvantages as well as the lack of objectivity in the analysis results so that it needs to be evaluated repeatedly. SMA (Sekolah Menengah Atas) is an upper secondary level of education in formal education after graduating from SMP (Junior High School). The number of students continuing their education to SMA Negeri is around 70\% and the remaining $30 \%$ will continue their education to private SMA. For students who will continue their education to private high schools, the parents and students are confused by the many choices of private high schools with various advantages and disadvantages. The CPI (Composite Performance Index) method is used to select several alternatives. The CPI technique is a composite index (Composite Index) that can be used to determine an assessment or ranking of various alternatives ( $i)$
\end{abstract}

Keywords: Students; SMA; CPI 


\section{PENDAHULUAN}

Penentuan sekolah sangat penting bagi orangtua untuk memperoleh pendidikan yang layak. Pemilihan sekolah merupakan masalah utama bagi orangtua disimpulkan dari hasil beberapa pertanyaan kepada orangtua. Banyaknya pilihan sekolah yang masing-masing memiliki kelebihan dan kekurangan serta kurang objektifnya data hasil analisa sehingga perlu dievaluasi berulangulang. SMA(Sekolah Menengah Atas) merupakan jenjang pendidikan menengah atas pada pendidikan formal setelah lulus SMP (Sekolah Menengah Pertama), SMP/MTS ditempuh dalam waktu 3 tahun mulai dari kelas 7 sampai kelas 9 . Kebanyakan siswa SMP yang akan melanjutkan ke jenjang SMA memilih SMA Negeri. Jumlah siswa yang melanjutkan pendidikan ke SMA Negeri sekitar 70\% dan $30 \%$ sisanya akan melanjutkan pendidikan ke SMA Swasta. Bagi siswa yang akan melanjutkan pendidikan ke SMA swasta, orang tua dan siswa tersebut dipusingkan dengan banyaknya pilihan SMA swasta yang ada dengan berbagai keunggulan dan kekurangan. Metode CPI(Composite Performance Index) digunakan untuk memilih beberapa alternatif[1]. Teknik CPI merupakan indeks gabungan (Composite Index) yang dapat digunakan untuk menentukan penilaian atau peringkat dari berbagai alternatif(i).

\section{TINJAUAN PUSTAKA}

\subsection{Penelitian Terdahulu}

Pertama, penelitian yang dilakukan Parlia Romadiana pada tahun 2016 dengan judul "Kajian Pemilihan SMA Swasta Terfavorit Sebagai Acuan Bagi Calon Siswa yang akan Melanjutkan Sekolah ke SMA Swasta di Kota Pangkalpinang". Pada penelitian ini dikatakan bahwa di kota Pangkalpinang terdapat banyak SMA Swasta yang saling bersaing baik dalam bidang fasilitas, tenaga pengajar, prestasi maupun kegiatan ekstrakulikuler. Hal itu membuat para siswa menjadi bingung dalam menentukan sekolah mana yang baik untuk mereka. Kajian pemilihan SMA

Swasta ini dibuat agar dapat dijadikan acuan bagi calon siswa untuk memilih SMA Swasta Terfavorit di Pangkalpinang dengan menggunakan metode Analitycal Hierarchy Process(AHP). AHP merupakan metode untuk memecakan suatu situasi yang tidak terstruktur ke dalam beberapa komponen dalam bentuk hierarki, member penilaian subjective yang diberikan oleh

responden ahli dengan tingkat konsistensi tidak kurang atau sama dengan $10 \%$ menggunakan software Expert Choice. Setelah dilakukan analisis dan perhitungan hasil quisioner, dapat disimpulkan bahwa SMA Swasta Terfavorit di Kota Pangkalpinang yaitu SMA Santo Yosef dengan bobot sebesar $46,9 \%$, dilanjutkan dengan SMA THB dengan bobot sebesar $29,6 \%$, dan alternatif yang terkecil yaitu SMA Swadaya dengan bobot sebesar $23,5 \%$ [2].

Kedua, penelitian yang dilakukan oleh Narti dkk, pada tahun 2019 dengan judul "Pengambilan Keputusan Memilih Sekolah Dengan Metode AHP”. Setiap orang tua pasti ingin anaknya mendaftar pada sekolah yang tepat. Orang tua tidak ingin salah pilih dalam memilihkan sekolah untuk anak-anaknya. Dalam memilih sekolah yang baik dan tepat tentunya bukanlah suatu hal yang mudah, hal tersebut disebabkan karena banyaknya pertimbangan-pertimbangan yang dilakukan untuk mendapat suatu pilihan sekolah yang tepat, serta banyaknya pilihan sekolah yang membingungkan masyarakat baik siswa maupun orang tuanya. Adanya pendukung keputusan ini dapat menjadi solusi untuk memberikan pertimbangan dalam membantu masyarakat pada proses pemilihan sekolah. Metode Analytical Hierarchy Process (AHP) merupakan 
metode yang memiliki struktur yang berhirarki serta memberikan kemudahan dalam menyederhanakan suatu permasalahan dari kriteria yang kompleks dengan berbagai pilihan alternatif yang ada, sehingga dapat mempercepat proses pengambilan keputusan dalam pemilihan sekolah. Metode AHP ini mampu menghasilkan hasil yang lebih konsisten serta yang dihasilkan adalah berdasarkan urutan ranking dari setiap alternatif yang ada. Hasil perhitungan metode AHP ini terdapat empat kriteria yang menjadi tolak ukur dalam melakukan pemilihan sekolah yaitu, biaya, kualitas sekolah, tujuan akhir lulusan, serta bakat dan minat. Hasil akhir dari pengolahan data dan pengujian metode AHP didapatkan bahwa Sekolah Menengah Atas (SMA) lebih unggul 0,373 atau 37,3\% sedangkan Sekolah Menengah Kejuruan (SMK) 0,370 atau 37,0\%, Madrasah Aliyah (MA) 0,257 atau $25,7 \%$ [3].

Ketiga, penelitian yang dilakukan oleh Suherni Prahesti dkk pada tahun 2017 dengan judul “ Sistem Rekomendasi Pemilihan Sekolah Menengah Atas (Sma) Sederajat Kota Malang Menggunakan Metode Ahp-Electre Dan Saw”. Pendidikan merupakan aspek yang penting bagi masyarakat. Salah satu jenjang pendidikan formal adalah pendidikan menengah yaitu Sekolah Menengah Atas (SMA). Sekolah adalah lembaga yang memberikan pengajaran untuk siswa dibawah pengawasan guru. Setiap tahun ajaran baru, siswa akan memilih sekolah terbaik yang sesuai dengan keinginannya. Terdapat banyak pilihan sekolah dengan berbagai tawaran yang diberikan. Dengan begitu, calon siswa akan mengalami kesulitan dalam menentukan sekolah yang sesuai dengan kriteria yang diinginkan. Penelitian ini bertujuan untuk memberikan rekomendasi sekolah berdasarkan kriteria yang diinginkan oleh calon siswa dengan menerapkan metode AHP-ELECTRE dan
SAW ke dalam sistem. Metode AHP digunakan dalam pembobotan dari setiap kriteria, metode ELECTRE melakukan klasifikasi alternatif yang masuk ke dalam kelompok direkomendasikan, dan SAW melakukan perankingan alternatif. Untuk pengujian, hasil pengujian akurasi sistem adalah sebesar 82,98\%. Hasil akurasi didapatkan dengan membandingkan hasil rekomendasi sistem dengan data yang telah didapatkan[4].

\subsection{Siswa}

Siswa adalah setiap orang yang resmi terdaftar untuk mengikuti pelajaran di dunia pendidikan. Siswa atau anak didik adalah salah satu komponen manusiawi yang menempati posisi sentral dalam proses belajarmengajar, dalam proses belajar mengajar siswa sebagai pihak yang ingin meraih citacita memiliki tujuan dan kemudian ingin mencapainya secara optimal. Siswa akan menjadi faktor penentu, sehingga dapat mempengaruhi segala sesuatu yang diperlukan untuk mencapai tujuan belajarnya[5].

\subsection{CPI(Composite Performance Index) \\ Metode Composite Performance} Index (CPI) Merupakan indeks gabungan (Composite Index) yang dapat digunakan untuk menentukan penilaian atau peringkat dari digunakan untuk menentukan penilaian atau peringkat dari berbagai alternatif berdasarkan beberapa kriteria[6]. Prosedur penyelesaian metode CPI adalah

1 Identifikasi kriteria tren positif (semakin tinggi nilainya semakin baik) dan tren negatif (semakin rendah nilainya semakin baik).

2 Untuk kriteria tren positif, nilai minimum pada setiap kriteria ditransformasi ke seratus, sedangkan nilai lainnya ditransformasi secara proporsional lebih tinggi. 
3 Untuk kriteria tren negatif, nilai minimum pada setiap kriteria ditransformasi ke seratus, sedangkan nilai lainnya ditransformasi secara proporsional lebih rendah.

Perhitungan CPI dapat dilihat seperti berikut:

$$
\begin{array}{ll}
\text { Aij } & =(X i j(\min ) / X i j(\min )) x \\
100 & \\
\text { A(I+ 1.j) } & =(X(i+1 . j)) / X i j(\min )) x \\
100 & \\
\text { Iij } & =\text { Aij x Pj } \\
\text { Ii } & =\sum i=1
\end{array}
$$

Ket :

$$
\begin{array}{ll}
\begin{array}{l}
\text { Aij } \\
\text { criteria ke }-\mathrm{j} \\
\text { Xij(min) }
\end{array} & \begin{array}{l}
\text { : Nilai alternatif ke-i pada } \\
\multicolumn{1}{c}{\text { Nilai alternatif ke-i pada }} \\
\text { criteria awal minimum ke }
\end{array} \\
\text { A(i+1.j) } & \begin{array}{l}
\text { : Nilai alternatif ke-i+1pada } \\
\text { criteria ke-j }
\end{array} \\
\text { X(i+1.j }) & \begin{array}{l}
\text { : Nilai alternatif ke-i+1pada } \\
\text { criteria awal ke-j }
\end{array}
\end{array}
$$

Pj $\quad$ : Bobot kepentingan criteria ke-j

Iij : Index alternatif ke-i

Ii : Indeks gabungan criteria alternatif ke-i$$
\text { I } \quad: 1,2,3, \ldots \ldots \text {. }
$$$$
\text { J } \quad: 1,2,3, \ldots \ldots m
$$

\section{METODOLOGI PENELITIAN}

\subsection{Analisa Sistem yang Berjalan}

Analisa Masalah dilakukan dengan melakukan pengamatan kepada calon siswa yang akan melanjutkan sekolah ke jenjang SMA swasta. Hasil dari pengamatan tersebut digunakan untuk menentukan kriteria dan sub kriteria penelitian. Selanjutnya menentukan alternative berdasarkan kebutuhan kriteria dan sub kriteria yang telah ditentukan. Alernatif dalam penelitian ini sebanyak 10 SMA Swasta yang yang memenuhi kriteria dan sub kriteria dalam pemilihan SMA swasta

\subsection{Alternatif Pemecahan Masalah}

Berdasarkan sistem yang berjalan maka alteratif yang ditawarkan penulis untuk menerapkan metode CPI proses penentuan pemilihan SMA Swasta yang ada.

\section{HASIL DAN PEMBAHASAN}

\section{Penentuan Kriteria}

Dari hasil pengumpulan data yang telah dilakukan, ditentukan empat kriteria pemilihan SMA Swasta dan dari empat criteria yang ada ditentukan tren positif dan tren negatif. Empat kriteria tersebut dapat dilihat pada Tabel 1.

Tabel 1. Tabel Kriteria Penilaian

\section{Kriteria Penilaian}

1. Peringkat Akreditasi ( Tren Negatif )

2. Jarak Lokasi dengan Pusat Kota ( Tren Negatif )

3. Kategori Biaya( Tren Negatif)

4. Kelengkapan Fasilitas( Tren Positif )

\section{Penentuan Skala dan Bobot Kriteria}

Tahap selanjutnya setelah penentuan criteria adalah menentukan skala dari kriteria dan menentukan bobot kriteria.

\section{Perhitungan Hasil Penilaian Kriteria} Setelah melakukan proses penentuan skala dan pembobotan kriteria, berikutnya adalah menentukan bobot setiap kriteria yang dinilai.

\section{Perhitungan Nilai Total Setiap Kriteria \\ Setelah melakukan proses} penilaian bobot kriteria, berikutnya adalah melakukan perhitungan total tiap kriteria yang nantikan hasil perhitungan ini akan digunakan dalam melakukan perhitungan nilai alternatif dan perengkingan. 
Tabel 2. Tabel Penentuan Skala dan Bobot Kriteria

\begin{tabular}{cc}
\hline \multicolumn{2}{c}{ Periangkat Akreditasi } \\
\hline Nilai & Bobot \\
A & 10 \\
B & 7,5 \\
C & 5 \\
D & 2,5
\end{tabular}

\begin{tabular}{cc}
\hline \multicolumn{2}{c}{ Jarak Lokasi dengan Pusat Kota } \\
\hline Jarak Lokasi & Bobot \\
$<1 \mathrm{Km}$ & 10 \\
$1-3 \mathrm{Km}$ & 7,5 \\
$3-5 \mathrm{KM}$ & 5 \\
$>5 \mathrm{KM}$ & 2,5 \\
\hline \multicolumn{2}{c}{ Kategori Biaya } \\
\hline Biaya & Bobot \\
Gratis & 10 \\
$<100.000$ & 7,5 \\
$150.000-300.000$ & 5 \\
$>300.000$ & 2,5 \\
\hline
\end{tabular}

Kelengkapan Fasilitas

Fasilitas

Sangat Lengkap

Lengkap
Cukup Lengkap

Tidak lengkap

Tabel 3. Tabel Penilaian Bobot Kriteria Penilaian

\begin{tabular}{|c|c|c|c|c|}
\hline $\begin{array}{l}\text { Nama } \\
\text { SMA }\end{array}$ & $\begin{array}{c}\text { Peringka } \\
\text { t } \\
\text { Akredita } \\
\text { si }\end{array}$ & $\begin{array}{c}\text { Jarak } \\
\text { Lokasi } \\
\text { dengan } \\
\text { Pusat } \\
\text { Kota(K } \\
\text { M) } \\
\end{array}$ & $\begin{array}{c}\text { Kateg } \\
\text { ori } \\
\text { Biaya }\end{array}$ & $\begin{array}{c}\text { kelengkap } \\
\text { an } \\
\text { Fasilitas }\end{array}$ \\
\hline SMA A & 10 & 5 & 2,5 & 10 \\
\hline SMA B & 10 & 2,5 & 2,5 & 10 \\
\hline SMA C & 10 & 7,5 & 2,5 & 10 \\
\hline SMA D & 7,5 & 10 & 5 & 7,5 \\
\hline SMA E & 7,5 & 10 & 5 & 7,5 \\
\hline SMA F & 10 & 2,5 & 2,5 & 7,5 \\
\hline SMA G & 7,5 & 5 & 2,5 & 7,5 \\
\hline SMA H & 7,5 & 7,5 & 10 & 7,5 \\
\hline SMA I & 7,5 & 5 & 10 & 7,5 \\
\hline SMA J & 7,5 & 5 & 10 & 5 \\
\hline
\end{tabular}

Tabel 4. Tabel Perhitungan Nilai Total Setiap Kriteria

\begin{tabular}{cclll}
\hline $\begin{array}{c}\text { Nama } \\
\text { SMA }\end{array}$ & \multicolumn{1}{c}{$\begin{array}{c}\text { Peringkat } \\
\text { Akreditasi(+) }\end{array}$} & $\begin{array}{c}\text { Jarak Lokasi dengan } \\
\text { Pusat Kota(KM)(-) }\end{array}$ & $\begin{array}{c}\text { Kategori } \\
\text { Biaya(-) }\end{array}$ & $\begin{array}{c}\text { kelengkapan } \\
\text { Fasilitas(+) }\end{array}$ \\
\hline SMA A & 133,3333333 & 50 & 100 & 10 \\
SMA B & 133,3333333 & 100 & 100 & 10 \\
SMA C & 133,3333333 & 33,33333333 & 100 & 10 \\
SMA D & 100 & 25 & 50 & 7,5 \\
SMA E & 100 & 25 & 50 & 7,5 \\
SMA F & 133,3333333 & 100 & 100 & 7,5 \\
SMA G & 100 & 50 & 100 & 7,5 \\
SMA H & 100 & 33,33333333 & 25 & 7,5 \\
SMA I & 100 & 50 & 25 & 7,5 \\
SMA J & 100 & 50 & 25 & 5 \\
\hline
\end{tabular}




\section{Perhitungan Nilai Alternatif}

Tahap selanjutnya dari metode CPI adalah menghitung nilai alternatif dari setiap kriteria penilaian. Penghitungan nilai alternatif dilakukan dengan mengalikan nilai total setiap criteria dengan bobot Kriteria. Hasil perhitungan nilai alternatif dapat dilihat pada Tabel 6 .

Tabel 5. Tabel Perhitungan Nilai Alternatif

\begin{tabular}{lcccc}
\hline Nama SMA & $\begin{array}{c}\text { Peringkat } \\
\text { Akreditasi(+) }\end{array}$ & $\begin{array}{c}\text { Jarak Lokasi } \\
\text { dengan Pusat } \\
\text { Kota(KM)(-) }\end{array}$ & $\begin{array}{c}\text { Kategori } \\
\text { Biaya(-) }\end{array}$ & $\begin{array}{c}\text { kelengkapan } \\
\text { Fasilitas(+) }\end{array}$ \\
\hline SMA A & 53,33333333 & 10 & 40 & 2 \\
SMA B & 53,33333333 & 20 & 40 & 2 \\
SMA C & 53,33333333 & 6,666666667 & 40 & 2 \\
SMA D & 40 & 5 & 20 & 1,5 \\
SMA E & 40 & 5 & 20 & 1,5 \\
SMA F & 53,33333333 & 20 & 40 & 1,5 \\
SMA G & 40 & 10 & 40 & 1,5 \\
SMA H & 40 & 6,666666667 & 10 & 1,5 \\
SMA I & 40 & 10 & 10 & 1,5 \\
SMA J & 40 & 10 & 10 & 1 \\
\hline
\end{tabular}

\section{Perhitungan Nilai Total Alternatif}

Tahap selanjutnya dari metode CPI adalah menghitung nilai total alternatif dari setiap kriteria penilaian. Penghitungan nilai total alternatif dilakukan dengan menjumlahkan seluruh nilai alternatif tiap kriteria. Hasil perhitungan nilai total alternatif dapat dilihat pada Tabel 6.

Tabel 6. Hasil perhitungan nilai total alternatif

\begin{tabular}{lccccc}
\hline Nama SMA & $\begin{array}{c}\text { Peringkat } \\
\text { Akreditasi(+) }\end{array}$ & $\begin{array}{c}\text { Jarak Lokasi } \\
\text { dengan Pusat } \\
\text { Kota(KM)(-) }\end{array}$ & $\begin{array}{c}\text { Kategori } \\
\text { Biaya(-) }\end{array}$ & $\begin{array}{c}\text { kelengkapan } \\
\text { Fasilitas(+) }\end{array}$ & \begin{tabular}{c} 
Total Alternatif \\
\hline SMA A
\end{tabular} \\
53,33333333 & 10 & 40 & 2 & 105,3333333 \\
SMA B & 53,33333333 & 20 & 40 & 2 & 115,3333333 \\
SMA C & 53,33333333 & 6,666666667 & 40 & 2 & 102 \\
SMA D & 40 & 5 & 20 & 1,5 & 66,5 \\
SMA E & 40 & 5 & 20 & 1,5 & 66,5 \\
SMA F & 53,33333333 & 20 & 40 & 1,5 & 114,8333333 \\
SMA G & 40 & 10 & 40 & 1,5 & 91,5 \\
SMA H & 40 & 6,666666667 & 10 & 1,5 & 58,16666667 \\
SMA I & 40 & 10 & 10 & 1,5 & 61,5 \\
SMA J & 40 & 10 & 10 & 1 & 61 \\
\hline
\end{tabular}

Dari seluruh proses perhitungan dengan metode CPI, didapat hasil akhir atau output berupa informasi perengkingan SMA dengan didasarkan dari nilai total seluruh alternatif dari kriteria yang ada. Informasi hasil perengkingan SMA dapat dilihat pada Tabel 7. 
Tabel 7. Hasil Perengkingan SMA

\begin{tabular}{ccc}
\hline $\begin{array}{c}\text { Nama } \\
\text { SMA }\end{array}$ & Total Alternatif & Peringkat \\
\hline SMA B & 115,3333333 & 1 \\
SMA F & 114,8333333 & 2 \\
SMA A & 105,3333333 & 3 \\
SMA C & 102 & 4 \\
SMA G & 91,5 & 5 \\
SMA D & 66,5 & 6 \\
SMA E & 66,5 & 7 \\
SMA I & 61,5 & 8 \\
SMA J & 61 & 9 \\
SMA H & 58,16666667 & 10 \\
\hline
\end{tabular}

\section{SIMPULAN}

Adapun simpulan penelitian tentang sistem pendukung keputusan untuk menentuan SMA swasta adalah sebagai berikut :

1. Sistem pendukung keputusan yang dibangun dengan menggunakan metode Composite Performance Index(CPI) dapat membantu perengkingan SMA swasta kriteria yang ditentukan.

2. Nilai total alternatif tertinggi dapat dijadikan pertimbangan dalam memilih SMA yang akan dijadikan tempat untuk melanjutkan pendidikan tingkat atas

\section{SARAN}

Saran untuk penelitian selanjutnya dengan tema yang sama adalah agar menggunakan lebih dari satu metode untuk mendapat hasil atau output yang lebih baik untuk membandingkan hasil dari metode yang satu dengan yang lainnya.

\section{DAFTAR PUSTAKA}

[1] R. M. Simanjorang, A. Gorry, and S. S. Morton, "Penerapan Metode Composite Performance Index Dalam Mendukung Pengambilan Keputusan Pemilihan Guru Terbaik ( Studi Kasus : Sdn 003 Pagaran Tapah )," Jurnal Mantik Penusa, vol. 2, no. 2. pp. 180-
184, 2018, [Online]. Available: http://e-

jurnal.pelitanusantara.ac.id/index. $\mathrm{php} / \mathrm{mantik} /$ article/download/510 1303 .

[2] P. Romadiana, "Kajian Pemilihan SMA Swasta Terfavorit Sebagai Acuan Bagi Calon Siswa yang akan Melanjutkan Sekolah ke SMA Swasta di Kota Pangkalpinang," J. SISFOKOM, vol. 5, no. 1, pp. 54-59, 2016.

[3] N.- Narti, S. Sriyadi, N. Rahmayani, and M. Syarif, "Pengambilan Keputusan Memilih Sekolah Dengan Metode AHP," Jurnal Informatika, vol. 6, no. 1. pp. 143-150, 2019, doi: 10.31311/ji.v6i1.5552.

[4] S. Prahesti, D. E. Ratnawati, and H. Nurwasito, "Sederajat Kota Malang Menggunakan Metode Ahp-Electre Dan," Jurnal Teknologi Informasi dan Ilmu Komputer (JTIIK), vol. 4, no. 1. pp. 25-30, 2017.

[5] I. D. Novitasari, "Upaya Guru Dalam Meningkatkan Keberanian Siswa Untuk Bertanya Pada Pembelajaran Pendidikan Kewarganegaraan," Artikel Publikasi Ilmiah, no. August. pp. 1-13, 2014.

[6] A. A. Tri Susilo, "Penerapan Metode CPI Pada Pemilihan Hotel Dikota Lubuklinggau," $J$. RESTI, vol. 1, no. 3, pp. 204-210, 2017. 